\title{
The Effects of Spatially Separated Call Components on Phonotaxis in Túngara Frogs: Evidence for Auditory Grouping
}

\author{
Hamilton E. Farris ${ }^{a}$ A. Stanley Rand ${ }^{b}$ Michael J . Ryan a,b \\ aSection of Integrative Biology, University of Texas-Austin, Austin, Tex., USA, and \\ bSmithsonian Tropical Research Institute, Balboa, Panama
}

\section{Key Words}

Auditory stream analysis · Cocktail party effect . Spatial masking $\cdot$ Calling song $\cdot$ Mate choice $\cdot$ Phonotaxis · Chorus · Amphibian · Frog · Túngara

\begin{abstract}
Numerous animals across disparate taxa must identify and locate complex acoustic signals imbedded in multiple overlapping signals and ambient noise. A requirement of this task is the ability to group sounds into auditory streams in which sounds are perceived as emanating from the same source. Although numerous studies over the past 50 years have examined aspects of auditory grouping in humans, surprisingly few assays have demonstrated auditory stream formation or the assignment of multicomponent signals to a single source in non-human animals. In our study, we present evidence for auditory grouping in female túngara frogs. In contrast to humans, in which auditory grouping may be facilitated by the cues produced when sounds arrive from the same location, we show that spatial cues play a limited role in grouping, as females group discrete components of the species' complex call over wide angular separations. Furthermore, we show that once grouped the sep-
\end{abstract}

\section{KARGER}

Fax +4161306 1234

E-Mail karger@karger.ch

www. karger.com
(C) 2002 S. Karger AG, Basel

Accessible online at: www. karger.com/bbe arate call components are weighted differently in recognizing and locating the call, so called 'what' and 'where' decisions, respectively.

Copyright $@ 2002$ S. Karger AG, Basel

\section{Introduction}

In considering receiver psychology in animal communication, Rowe [1999] proposed a continuum for the perception of complex signals and their components. At one end of the continuum, each signal component is perceived separately and the receiver's response to the presentation of the multicomponent complex is predicted from the responses to each component presented alone [Narins and Capranica, 1978]. The other end of the continuum, however, considers each component as a contributor to a complex, differing from the sum of its parts. In some systems this compound may be scaled to a dimension such as signal complexity, which receivers may score when comparing signals. This type of perception is illustrated by receivers that prefer signal complexity per se [Mounjoy and Lemon, 1991, 1996] and preferences are correlated to the number of components composing the complex; these preferences might result in the evolution of signals that 
Fig. 1. a Spectrogram and oscillogram of a complete call. b Diagram of the phonotaxis arena and example of one stimulus condition. Five speakers at $45^{\circ}$ separation were configured along the perimeter of a $75 \mathrm{~cm}$ radius circle on the floor of a sound chamber. Stimuli consisted of a whine and/or a chuck presented together or alone. After release in the center of the arena, female position and exit angle were recorded using an infrared camera and video recorder. For the categorical analysis, because frogs exiting the arena within $13 \mathrm{~cm}$ of the center of a speaker could still make contact with a speaker-case, all responses $\pm 10^{\circ}$ of the center of a particular speaker were scored as a positive response to that speaker. c Each point represents the exit angle (re: whine position) for one female $P$. pustulosus presented with a whine or a chuck alone or in combination with varying spatial separation. $p$ values are shown for a Fisher exact test comparing chuck attractiveness when presented with the whine to that when presented alone. Chuck amplitude was $6 \mathrm{~dB}$ re: whine amplitude ( $90 \mathrm{~dB}$ SPL).

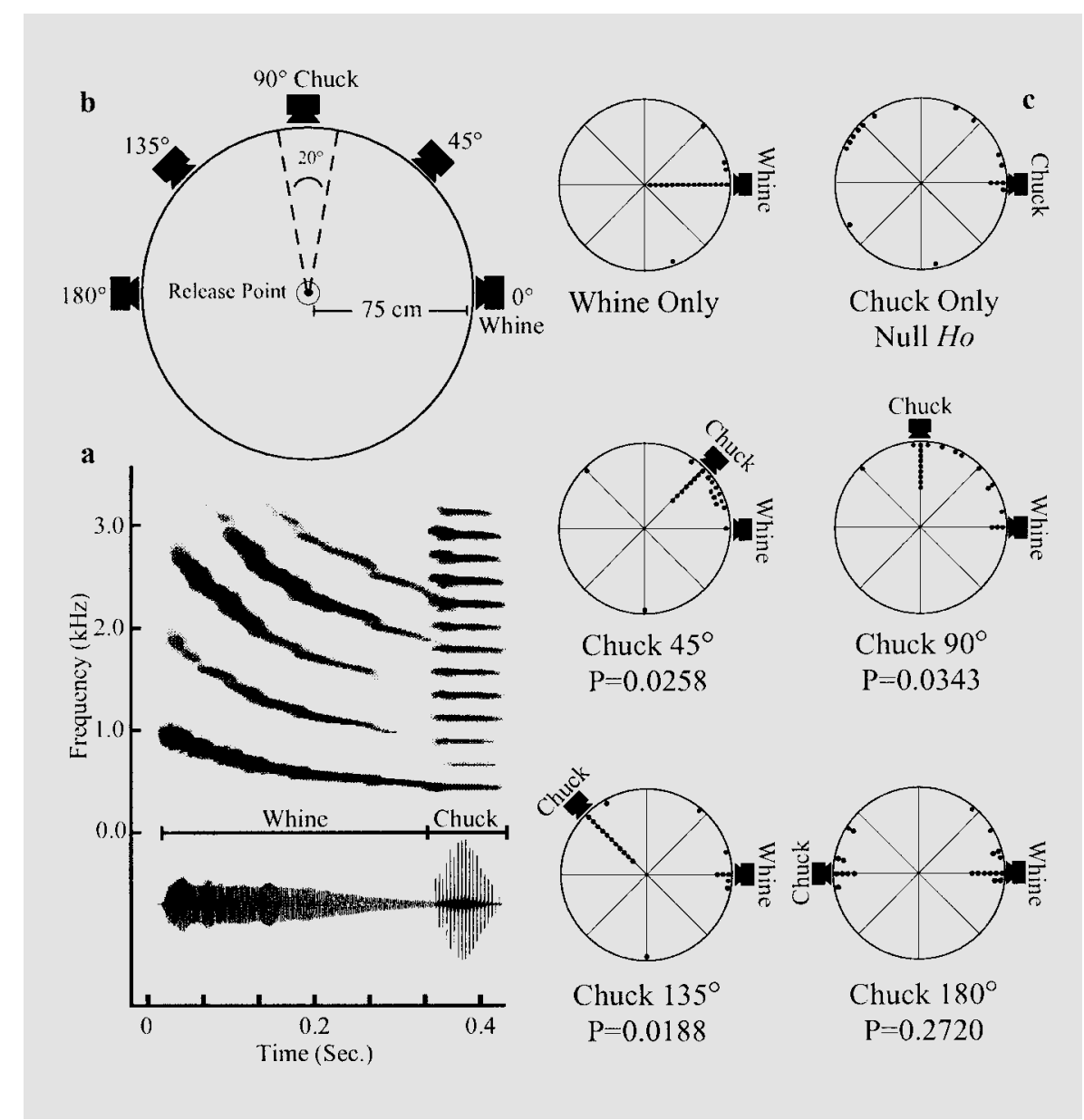

avoid receiver habituation [Nottebohm, 1972; Krebs, 1976; Searcy, 1992]. In others systems, however, perceptual interactions among components can lead to the alerting [Richards, 1981] or amplifying [Vander Meer et al., 1990] of one component by another. Here, a component's behavioral significance may only be perceived if it is part of the complex [Hölldobler, 1995, 1999].

Whether or not a stimulus is perceived as a complex, however, is determined by the receiver's ability to perceptually group the components. Although critical to the processing of complex stimuli, comparatively little research has addressed the limitations of this ability in animals, with most of our understanding drawn from tests with humans. For example, the 'cocktail party effect' refers to the ability of human listeners to attend to sounds produced by one source while rejecting interference from others [Cherry, 1953]. Inextricably linked to this ability is the capacity to associate sounds into groups (e.g., auditory streams) [Bregman, 1990] so that they can be recognized and assigned to their sources. Although studies of various animals have shown that complex signal components from the same source can interact perceptually (and thus may be processed as a stream) [Ratcliffe and Weisman, 1986; Mac Dougall-Shackleton et al., 1998; Ghazanfar et al., 2001; Moss and Surlykke, 2001], the spatial limitations on such stream perception and its potential influence on the behavioral significance of the components in the complex have not been considered in non-human taxa. Thus, although non-humans are faced with a similar perceptual problem as humans, comparatively little is known about their abilities and limitations in such perceptual tasks [Feng and Ratnam, 2000].

To address this problem, we measured phonotactic responses to spatially segregated call components in female túngara frogs (Physalaemus pustulosus). The complex calls of $P$. pustulosus contain two distinct components, the whine and the chuck (fig. 1a), which are commonly produced by males in multi-male choruses [Ryan, 
1980]. All calls contain a whine, which is necessary and sufficient to elicit phonotaxis from females. Although the chuck alone does not elicit phonotaxis, its addition to the whine results in a more attractive call than the whine alone [Ryan, 1980; Ryan and Rand, 1990]. This phonotactic preference for the whine and chuck stimulus is maintained even when the whine alone (i.e., simple call) is increased in total energy [Ryan and Rand, 1990] or has the same duration as the complex [Wilczynski et al., 1999], suggesting that the components are meaningful perceptual units grouped as a stream. The presentation of spatially segregated call components allowed us to measure the spatial requirements for auditory grouping while simultaneously measuring the behavioral significance of each component in the complex. Thus, whereas the goal of previous studies examining multicomponent sexual signals has been limited to simply identifying the meaningful units in the complex [Nelson, 1988; Nelson and Croner, 1991; Ghazanfar et al., 2001], we show that phonotaxis in túngara frogs is uniquely suitable for identifying what these units mean.

\section{Materials and Methods}

\section{Subjects}

Prior to testing, females $(n=22)$ were collected in amplexus in Gamboa, Panama approximately $3 \mathrm{~h}$ after sunset. Because all animals were returned to the field following the trials, animals were marked (toe clipped) to prevent retesting on subsequent nights. All procedures with animal subjects were performed in accordance with the guidelines established by the Smithsonian Tropical Research Institute and the University of Texas at Austin Animal Care and Use Committee.

\section{Experimental Procedure}

Phonotactic responses were measured to whines and chucks presented alone or in combination at various spatial separations $(0,45$, 90,135 and $\left.180^{\circ}\right)$. For each trial, gravid females of P. pustulosus were placed beneath a plastic cone $(10 \mathrm{~cm}$ diameter $)$ at the center of a circular array of 5 speakers on the floor of the sound chamber (fig. 1b). Following $3 \mathrm{~min}$ of exposure to the stimuli, the cone was removed allowing a subject to move freely. Using an infrared camera, we (minimum of 3 observers) recorded the position (in $5^{\circ}$ intervals) at which females exited the full perimeter. A positive response was recorded only if the female crossed the perimeter of the array within 15 min. 'No-choice' trials were scored when females (1) failed to leave the $10 \mathrm{~cm}$ center circle in $5 \mathrm{~min}$, (2) remained stationary for $2 \mathrm{~min}$, or (3) remained within the perimeter for $15 \mathrm{~min}$. To ensure that 'no-choice' scores were due to the stimuli and not a lack of female motivation, females exhibiting consecutive 'no-choice' responses were not tested further. Twenty of 22 females completed the entire sequence with the individuals tested only once per stimulus separation angle. At all times during the experiments (i.e., in or out of the cone), subjects controlled their orientation with respect to the speakers. All trials were performed within $12 \mathrm{~h}$ of sunset under infrared illumination only. Ambient temperature for all experiments was $26.5-27.4^{\circ} \mathrm{C}$. The experiments were repeated at two different relative amplitudes of the two components within the natural range produced by males (chuck:whine $=0$ or $6 \mathrm{~dB} ; 90$ or $96 \mathrm{~dB}$ SPL). When presented alone, the amplitude of the chuck stimulus was $6 \mathrm{~dB}$ (re: whine amplitude, $90 \mathrm{~dB}$ SPL). Although the sequence of stimuli was presented randomly with respect to spatial position, the sequence alternated between stimuli containing high and low relative amplitude chucks (including the chuck-only condition). Furthermore, the whine-only stimulus was always presented at the end of the 12-stimulus sequence.

We used both categorical and circular analyses to assess the effects of the whine-chuck complex on chuck attractiveness and phonotaxis direction, respectively. For the categorical analysis, exit angles were grouped into one of two categories. The first category included those responses in which females exited the perimeter by making contact with the speaker broadcasting the chuck (a $20^{\circ}$ arc; $13 \mathrm{~cm}$ ), and the second category consisted of all other exit angles as well as those trials exhibiting 'no choice' responses (fig. 1b). A Fisher exact test was used to compare the probability of phonotaxis to chucks broadcast with the whine to that for the simple broadcast condition (i.e., chuck-only, which served as the null hypothesis).

With respect to circular analyses, the effect of chuck position on phonotactic direction was analyzed using either a Rayleigh test for circular uniformity or a V-test, which determines whether responses are localized at a particular exit angle [Zar, 1999]. Unlike the categorical analysis, these analyses were restricted to trials in which the females exited the perimeter, excluding 'no choice' responses. For cases in which responses appeared to fall in symmetrical, bimodal distributions, exit angles were transformed to a unimodal distribution [Zar, 1999] so that the distribution axis could be determined using a V-test. Differences in mean exit angles between various broadcast conditions were analyzed using a Watson-Williams test [Zar, 1999] with alpha correction (i.e., Bonferroni) for multiple comparisons.

\section{Stimuli}

We used an average call from one of the sites that yielded some of the collected females. We analyzed 250 complex calls of 50 males (five calls per male) and measured 14 acoustic variables of the whine and chuck. The data were analyzed by multiple dimensional scaling to reduce the multivariate data to a two-dimensional map. We then chose the call at the center of the distribution as representing a 'typical' or 'average' call for the population. Call period for all stimuli was $2 \mathrm{~s}$.

Stimuli were generated using Signal 16 bit, digital-to-analog converters and software ( $44.4 \mu$ s sample period). Stimuli were amplified using a Pioneer A-105 amplifier and broadcast from either Radioshack 4 inch broadband speakers (Cat. \# 40-1040) or ADS (L200C) speakers positioned along the perimeter of a $75 \mathrm{~cm}$ radius arc inside an Acoustic Systems (Austin, Tex., USA) sound chamber $(2.75 \times$ $1.83 \mathrm{~m}$ ) lined with additional anechoic foam along the bottom $0.6 \mathrm{~m}$ of each wall (Sonex, 1.5 inch; NRC 0.8). Prior to each night's trials, the peak amplitude of the whine and chuck stimuli were calibrated using a $500 \mathrm{~Hz}$ continuous tone, a GenRad 1982 sound level meter (Fast, linear weighting) and 0.5 inch microphone placed $3 \mathrm{~cm}$ above the floor of the arena at the center of the arc (grid on, $90^{\circ}$ angle of incidence). All sound pressure levels (dB SPL) are referenced to $20 \mu \mathrm{Pa}$. To reduce any phonotactic bias due to potential speaker vari- 
Table 1. Categorical analysis of chuck attractiveness in simple vs. complex broadcasts

\begin{tabular}{|c|c|c|c|c|}
\hline $\begin{array}{l}\text { Angle of chuck } \\
\text { (re: whine) }\end{array}$ & $\begin{array}{l}\text { Attracted } \\
\text { to chuck }\end{array}$ & $\begin{array}{l}\text { Non-chuck } \\
\text { responses }\end{array}$ & Total & $\begin{array}{l}\text { Fisher } \\
\text { exact } p\end{array}$ \\
\hline \multicolumn{5}{|l|}{ Chuck only } \\
\hline Null $H o$ & 4 & 17 & 21 & - \\
\hline \multicolumn{5}{|l|}{ High Amp } \\
\hline $0^{\circ}$ & 18 & 3 & 21 & 0.00002 \\
\hline $45^{\circ}$ & 11 & 10 & 21 & 0.0258 \\
\hline $90^{\circ}$ & 11 & 11 & 22 & 0.0343 \\
\hline $135^{\circ}$ & 11 & 9 & 20 & 0.0188 \\
\hline $180^{\circ}$ & 7 & 15 & 22 & 0.2720 \\
\hline \multicolumn{5}{|l|}{ Low Amp } \\
\hline $0^{\circ}$ & 17 & 3 & 21 & 0.00003 \\
\hline $45^{\circ}$ & 12 & 9 & 21 & 0.0123 \\
\hline $90^{\circ}$ & 4 & 16 & 20 & 0.6220 \\
\hline $135^{\circ}$ & 10 & 11 & 21 & 0.0501 \\
\hline $180^{\circ}$ & 4 & 18 & 22 & 0.6784 \\
\hline \multicolumn{5}{|c|}{$\begin{array}{l}\text { Table shows an increased response to the chuck stimulus when } \\
\text { presented with the whine. Columns are the angle of the chuck stimu- } \\
\text { lus (re: the whine position) for the high and low amplitude chuck } \\
\text { conditions, number of individuals attracted to the chuck, number of } \\
\text { non-chuck responses, total responses and p value for the Fisher exact } \\
\text { comparison using the responses to the chuck-only stimulus as the null } \\
\text { hypothesis. }\end{array}$} \\
\hline
\end{tabular}

ability, we randomly switched speakers between positions along the array after half of the frogs had been tested and varied the orientation for each broadcast condition in every trial. The latter also controlled for potential position effects introduced by the chamber.

\section{Results}

As previously shown [Ryan, 1985; Ryan and Rand, 1990] and reconfirmed here, females rarely exhibit phonotaxis to a chuck alone (fig. 1c; table 1). Thus, if females respond to a chuck from one speaker while a whine is being played from a different speaker, the females are potentially grouping the whine and the chuck. Phonotaxis to the spatially separated chuck occurred when it was presented with the whine over a wide range of separation angles (fig. 1c). Females were more likely to show phonotaxis to a chuck when it was closer to a whine and when the chuck had greater relative amplitude (table 1). When the chuck's amplitude was twice that of the whine's, attraction to the chuck was maintained over an angular separation of $135^{\circ}$. When the two components were of
Table 2. Relationship between chuck position and direction of phonotaxis

\begin{tabular}{llrll}
\hline $\begin{array}{l}\text { Angle of chuck } \\
\text { (re: whine) }\end{array}$ & $\mathrm{n}$ & $\begin{array}{l}\text { Mean } \\
\text { angle, }\end{array}$ & $\begin{array}{l}\text { Vector } \\
\text { length, } \mathrm{r}\end{array}$ & $\mathrm{p}$ \\
\hline $\begin{array}{l}\text { High Amp } \\
0^{\circ}\end{array}$ & 21 & 6.30 & 0.946 & $<0.0005$ \\
$45^{\circ}$ & 21 & 35.04 & 0.843 & $<0.0005$ \\
$90^{\circ}$ & 22 & 67.10 & 0.805 & $<0.0005$ \\
$135^{\circ}$ & 20 & 101.40 & 0.429 & $<0.0025$ \\
$180^{\circ}$ & 22 & 38.90 & 0.222 & $>0.1$ \\
\hline Low Amp & & & & \\
$0^{\circ}$ & 20 & 1.21 & 0.991 & $<0.0005$ \\
$45^{\circ}$ & 21 & 25.85 & 0.887 & $<0.0005$ \\
$90^{\circ}$ & 20 & 28.25 & 0.698 & $<0.0025$ \\
$135^{\circ}$ & 21 & 67.25 & 0.413 & $>0.1$ \\
$180^{\circ}$ & 22 & 12.18 & 0.671 & $>0.25$ \\
\hline Whine only, $0^{\circ}$ & 21 & 0.64 & 0.947 & $<0.0005$ \\
\hline
\end{tabular}

Columns are the angle of the chuck stimulus (re: the whine position) for the high and low amplitude chuck conditions, number of individuals exhibiting positive responses, mean exit angle, length of the mean vector (varies from 0 to 1 and is inversely correlated to the variance in exit angles), and $\mathrm{p}$ value for a $\mathrm{V}$-test for circular uniformity at the position of the chuck speaker (whine alone is tested at $0^{\circ}$ ).

equal amplitude, however, responses to the chuck were statistically significant only at $45^{\circ}$, although an almost significant response was recorded for the $135^{\circ}$ separation (table 1). Note that because whine-chuck spatial separation affects the conditional responses to the chuck, the unattractiveness of the chuck-only stimulus can not be the result of temporal isolation from a whine.

In addition to grouping the complex call components, females appear to weigh the components differently in processing call identity and location. Although phonotaxis is elicited only in the presence of the whine (table 1), its direction appears to depend on the presence or absence of a chuck. Whereas exit angles to the chuck-only stimulus are randomly distributed (Rayleigh test: $\mathrm{N}=16, \mathrm{Z}=1.34$, $\mathrm{p}>0.2$ ), exit angles for the complex stimuli are significantly localized at the positions of the chuck up to the 135 and $90^{\circ}$ separations in the high and low amplitude conditions, respectively (table 2). Furthermore, significant shifts in mean exit angle were revealed for even the smallest changes in chuck position (e.g., mean exit angle at $45^{\circ}$ separation differs from that at $0^{\circ}$; table 3 ).

For certain separations in which the chuck is no longer attractive, the circular analysis suggests that phonotaxis is 
Table 3. Direction of phonotaxis for separated and unseparated calls

\begin{tabular}{llcc}
\hline $\begin{array}{l}\text { Angle of chuck } \\
\text { (re: whine) }\end{array}$ & $\mathrm{n}$ & $\begin{array}{l}\text { Mean } \\
\text { angle, }\end{array}$ & $\mathrm{p}$ \\
\hline $\begin{array}{l}\text { High Amp } \\
0^{\circ}\end{array}$ & 21 & 6.30 & - \\
$45^{\circ}$ & 21 & 35.04 & $<0.0011^{*}$ \\
$90^{\circ}$ & 22 & 67.10 & $<0.0001^{*}$ \\
$135^{\circ}$ & 20 & 101.40 & $<0.0001^{*}$ \\
$180^{\circ}$ & 22 & 38.90 & 0.372 \\
\hline Low Amp & & & \\
$0^{\circ}$ & 20 & 1.21 & - \\
$45^{\circ}$ & 21 & 25.85 & $<0.0005^{*}$ \\
$90^{\circ}$ & 20 & 28.25 & 0.019 \\
$135^{\circ}$ & 21 & 67.25 & $<0.0006^{*}$ \\
$180^{\circ}$ & 22 & 12.18 & 0.595 \\
\hline Whine only, $0^{\circ}$ & 21 & 0.64 & 0.602 \\
\hline
\end{tabular}

Comparison of mean exit angles for spatially separated calls to that with $0^{\circ}$ separation using a Watson-Williams test [Zar, 1999] with alpha correction for multiple comparisons $(\alpha=0.0125)$. Note that the mean exit angle for the whine only stimulus is compared to that for the high amplitude chuck condition. Asterisks mark significant differences from the $0^{\circ}$ condition.

redirected to the whine. For example, at the $180^{\circ}$ separation for the high-amplitude broadcasts exit angles are more evenly distributed between the whine and chuck and thus not significantly grouped at the chuck position (table 2). Conversion of these data to a unimodal distribution confirms that the data are axial and consistent with a symmetrical bimodal distribution (table 4). Together, the categorical and circular analyses show that the whine is processed for both its identity and location, whereas the chuck appears to be processed only for location.

\section{Discussion}

\section{Perception of a Complex}

Both intra- and interspecific background noise may decrease the ability of female frogs to detect individual signaling males [Zelick and Narins, 1988]. Consequently female frogs, similar to humans, appear to make use of spectral [Ehret and Gerhardt, 1980], temporal and spatial [Schwartz and Gerhardt, 1989, 1995; Schwartz, 1993] cues to increase signal-to-noise ratios and improve their ability to choose among males in a chorus. With regard to spatial processing, previous studies have primarily ascer-
Table 4. Test for axial and bimodal exit angle distributions

\begin{tabular}{lclll}
\hline & $\begin{array}{l}\text { Mean exit } \\
\text { angle } \\
\text { unimodal }\end{array}$ & $\begin{array}{l}\text { Mean } \\
\text { vector, } \mathrm{r} \\
\text { unimodal }\end{array}$ & b-test at $0^{\circ}, \mathrm{p}$ & \multicolumn{2}{l}{ bimodal } & unimodal \\
\hline $180^{\circ}$ high & $2.05^{\circ}$ & 0.845 & $>0.05$ & $<0.0005$ \\
$180^{\circ}$ low & $11.00^{\circ}$ & 0.858 & $<0.0005$ & $<0.0005$ \\
\hline
\end{tabular}

Unimodal conversion of exit angles for the $180^{\circ}$ whine-chuck separations [Zar, 1999]. Columns are the mean exit angle, vector (cf. table 2 ) and $\mathrm{p}$ values for a $\mathrm{V}$-test for circular uniformity at $0^{\circ}$ before and after conversion. Significant clumping at $0^{\circ}$ after conversion for the high amplitude conditions suggests that the exit angles are bimodal and axial.

tained the ability of females to discriminate spatially separated calls (i.e., pairs of complete calls) or calls and noise [Schwartz, 1993; Schwartz and Gerhardt, 1995; Wollerman, 1999]. In designing our study, we originally intended to build on such previous work by trying to find the maximum spatial separation between a whine and chuck that would still produce the previously shown increase in attractiveness of the complex call relative to a whine alone [Ryan, 1985; Wilczynski et al., 1999]. Although methodologically similar to those studies cited above, this task has one important difference: rather than perceptually segregating two complete calls (i.e., from separate males), $P$. pustulosus females were asked to group the temporally and spectrally dissimilar components of a single complex call. From a comparative point of view, this perceptual difference is illustrated in humans by their drastically different spatial limits for auditory grouping and those for spatial masking and minimal audible angle [cf. Cherry, 1953; Grantham, 1995; see below]. In preliminary trials, however, we found that in the presence of a whine, the spatially separated chuck itself became attractive. Thus, we used this differential response to the individual components in the complex to not only measure the spatial requirements for auditory grouping, but also simultaneously assess the relative weighting of the two components in so-called 'what' and 'where' decisions (i.e., recognition and location, respectively).

Our results reveal evidence for both the perceptual independence of and modulation between the complex call components in túngara frogs, thus spanning the continuum proposed by Rowe [1999]. For example, with respect to their perceptual independence, the different weights applied to the whine and chuck in recognition and 
location decisions are similar to those demonstrated for the separate components of the dance language of honeybees [Apis mellifera; von Frisch, 1993]. Using a robot bee to control the stimuli produced in both the wagging and return runs of the waggle dance, Michelsen and colleagues showed that waggle direction and duration are weighed differently by recruited foragers in orientation and distance decisions, respectively [Michelsen and Andersen, 1989; Michelsen et al., 1992]. Interestingly, although greater relative weight appears to be applied to the chuck for location decisions, its attractiveness is modulated by the presence of a whine, a characteristic of the other end of the proposed continuum. The conditional response to the chuck is similar to the perceptual modulation within multicomponent signals in certain birds and insects. For example, when presented alone, the introductory component in the songs of rufous-sided towhees (Pipilo erythrophthalmus) elicits little or no response. In combination with subsequent song components, however, it appears to play the role of an alerting stimulus, modulating the probability of detecting the subsequent components and leading to a stronger response [Richards, 1981]. An analogous phenomenon has recently been documented in katydids. The song of Conocephalus brevipennis has at least two components, the so called ticks and short buzz. Although neither component elicits phonotaxis when presented alone, females are attracted to the short buzz when given a choice between the two [Guerra and Morris, 2002]. Modulation among signal components is not limited to the acoustic modality, however. Similar to the whine's gating of attraction to the chuck, the chemical signals used to recruit and orient worker ants (Solenopsis invicta) to food sources elicit little or no response unless grouped with a third 'inducer' chemical component [Vander Meer et al., 1990; Hölldobler, 1995]. In contrast to these examples, however, the 'inducer' component in the complex call of túngara frogs (i.e., the whine) elicits a response when presented by itself. Thus, the perceptual modulation described in our study includes not only a form of induction, but also a transfer of salience from one component to another.

\section{Source Determination}

Perceptual modulation of the chuck notwithstanding, the phenomenon of auditory grouping includes assigning the components of the complex to the same source. Yost and Sheft [1993] noted that although the phenomenon has been variously called auditory scene analysis, perception of auditory entities, auditory object perception or auditory image analysis, the underlying theme is the perception of individual sources amidst a complex of overlapping stimuli. It is difficult, however, to measure source determination of complex stimuli in non-humans and is often inferred from tests that measure differing responses to one stimulus complex over another [Mac Dougall-Shackleton et al., 1998; Moss and Surlykke, 2001]. This criterion is also consistent with perceptual modulation among stimuli, and not necessarily the result of assigning components of the complex to the same source. While our data clearly demonstrate different responses to the complex (i.e., or group) relative to the individual components (table 1), evidence for single source determination is revealed by the effect of spatial separation on phonotactic responses. Although robust to surprisingly wide separations, the whine's effect on chuck attractiveness decreases with increasing separation (tables 1-3), an effect inconsistent with simple perceptual modulation. Thus, similar to those studies that measure responses to spatially separated complete calls [Schwartz and Gerhardt, 1995], our results are consistent with the responses predicted for single source determination.

Studies of the function of sexual signals in any modality often assume that overlapping signals are processed by ideal receivers that do not make mistakes when assigning signals to their senders. Our study, however, reveals that complex call components in túngara frogs appear to be assigned to their (i.e., single) source with little use of spatial cues, potentially leading to mistakes during phonotaxis within a chorus. For example, could male attractiveness be transferred from one male in a chorus to another? Although males are known to affect the salience of competitors [Greenfield, 1994], we know of no system in which 'perceptual satellites' cause such a transfer. Our results raise this as a new possibility, however, for the function of complex call components in systems in which individuals produce overlapping calls.

\section{Spatial Acuity and Grouping}

In behavioral assays, the degree of spatial or directional auditory acuity measured in frogs depends on the type of assay used. For example, when using the accuracy of phonotaxis to a single sound source (i.e., head scanning and jump accuracy) Rheinlaender et al. [1979] measured spatial acuity on the order of $12^{\circ}$ in Hyla cinerea. Such acuity is consistent with measures of spatially mediated masking release in this species, as measures of call detection significantly improve for separations of calls and noise of $45^{\circ}$ [Schwartz and Gerhardt, 1989]. In contrast, however, larger separations in pairs of calls are required for frogs to recognize call patterns. In tests more similar to 
the grouping experiments presented in our study, female $H$. versicolor appear to require an order of magnitude greater call separation to perceptually segregate temporally overlapping calls, as separations of $120^{\circ}$ were required to elicit phonotaxis [Schwartz and Gerhardt, 1995]. Although similar underlying mechanisms might be involved in these tasks, such different degrees of acuity suggest that they are the result of different processes. Our study found that, similar to $H$. versicolor and humans, $P$. pustulosus females also show differences in their spatial capabilities in auditory grouping and directional tasks, illustrated by the difference between the large tolerances for spatial separation in auditory grouping and their ability to localize $\left( \pm 10^{\circ}\right.$ degrees) the speakers in phonotaxis. This similarity notwithstanding, however, further tests are required to determine whether their spatial acuity is comparably better than grouping acuity and thus consistent with the smaller measures found in other taxa.

\section{Specialized Signal Design}

A receiver's sensitivity can affect signal design. Similar to the transmission constraints imposed on signals by the environment, the biophysical limitations of a sensory system can determine which signal design is best for transmitting certain information [Bradbury and Vehrencamp, 1998]. With respect to sound localization in humans (and many other terrestrial animals), broadband sounds are more accurately located than those with narrow bands as a result of the ability to compare interaural time and intensity differences across multiple frequency channels [i.e., critical bands; Wightman and Kistler, 1993]. Such differences are due to the effects of the head related transfer function (i.e., the change in sound as it propagates from ear to ear) on sound propagation, illustrating a physical constraint on accuracy in localization tasks. Presently, however, it is unclear whether the chuck's favored use in localization decisions is based on its greater relative bandwidth. For example, in frogs, whether or not broader band sounds actually stimulate more auditory channels depends on the frequencies. With respect to the chuck, the increase in spectrum relative to the whine is primarily distributed in the sensitivity range of the basilar papilla, a single channel organ unable to contribute multiple frequency channels for directional comparisons [Ryan et al., 1990]. Furthermore, even when broader spectrum calls presumably do stimulate more critical bands, frogs do not necessarily demonstrate greater accuracy [Rheinlaender et al., 1979]. Besides having a greater bandwidth than the whine, the chuck also contains higher frequencies. Although some neurophysiological evidence in other frogs suggests greater directional sensitivity to higher frequencies [Feng, 1980; Feng and Schellart, 1999; Lin and Feng, 2001], behavioral assays have not [Rheinlaender et al., 1979]. Thus, further research is necessary to determine whether the acoustic characteristics of the chuck (i.e., broader band and higher frequencies) are processed with a greater relative degree of directional information than those of the whine.

\section{Conclusion}

Understanding the characteristics of auditory scene analysis and its underlying mechanisms is considered one of the 'biggest challenges' facing auditory researchers [Feng and Schellart, 1999; Feng and Ratnam, 2000]. In animal bioacoustics, part of this challenge is derived from the lack of available assays that demonstrate stream formation or the assignment of multicomponent signals to a single source. Thus, our results are important because they not only show stream formation but also a perceptual interaction which operationally results in the transfer of salience from one component in the stream (the whine) to another (the chuck). Whereas interpretation of the chuck's function in previous studies had been to add to the whine's attractiveness [Ryan, 1983], a more appropriate interpretation might be that the whine bestows saliency on the chuck which is more heavily weighed in directional phonotactic decisions.

\section{Acknowledgments}

Helpful input to this project was generously provided by: Rex Cocroft, Dennis McFadden, William Geisler, Tim Forrest, Melissa Redford, Carl Gerhardt and Walt Wilczynski. We sincerely thank X. Bernal, F. V. Candioti and K. Lynch for assistance with experiments. This paper benefited from the comments of two anonymous reviewers. This research was supported by NSF IBN 98 16564, and a Smithsonian Scholarly Studies Grant to M.J.R. and A.S.R. H.E.F. was supported by funds from the College of Natural Science, University of Texas at Austin. We thank the Smithsonian Tropical Research Institute for the their hospitality and logistical support. 


\section{References}

Bradbury, J.W., and S.L. Vehrencamp (1998) Principles of Animal Communication. Sinauer Associates, Sunderland, MA.

Bregman, A.S. (1990) Auditory Scene Analysis: The Perceptual Organization of Sound. MIT Press, Cambridge, MA.

Cherry, E.C. (1953) Some experiments on the recognition of speech, with one and two ears. J. Acoust. Soc. Am., 25: 975-979.

Ehret, G., and H.C. Gerhardt (1980) Auditory masking and effects of noise on responses of the green treefrog (Hyla cinerea) to synthetic mating calls. J. Comp. Physiol. 141: 13-18.

Feng, A.S. (1980) Directional characteristics of the acoustic receiver of the leopard frog (Rana pipiens): A study of the eighth nerve auditory responses. J. Acoust. Soc. Am., 68: $1107-$ 1114.

Feng, A.S., and R. Ratnam (2000) Neural basis of hearing in real-world situations. Ann. Rev. Psychol., 51: 699-725.

Feng A.S., and N.A.M. Schellart (1999) Central auditory processing in fish and amphibians. In Comparative Hearing: Fish and Amphibians (ed. by R. R. Fay and A. N. Popper), Springer Verlag, New York, pp. 218-268.

Frisch, K. von (1993) The Dance Language and Orientation of Bees. Harvard University Prss, Cambridge, MA.

Ghazanfar, A.A., J.I. Flombaum, C.T. Miller, and M.D. Hauser (2001) The units of perception in the antiphonal calling behavior of cotton-top tamarin (Saguinus oedipus): playback experiments with long calls. J. Comp. Physiol., 187 . 27-35.

Grantham D. W. (1995) Spatial hearing and related phenomena. In Hearing (ed. by B. C. J. Moore), Academic Press, New York, pp. 297-345.

Greenfield, M.D. (1994) Cooperation and conflict in the evolution of signal interactions. Ann. Rev. Ecol. Syst., 25: 97-126.

Guerra, P.A., and G.K. Morris (2002) Calling communication in meadow katydids (Orthoptera, Tettigoniidae): female preferences for speciesspecific wingstroke rates. Behaviour, 139: 23 43.

Hölldobler, B. (1995) The chemistry of social regulation: multicomponent signals in ant societies. Proc. Nat. Acad. Sci., 92: 19-22.

Hölldobler, B. (1999) Multimodal signals in ant communication. J. Comp. Physiol., 184: 129_ 141.

Krebs, J.R. (1976) Habituation and song repertoires in the great tit. Behav. Ecol. Sociobiol., 1: 215-227.
Lin, W.-Y., and A.S. Feng (2001) Free-field unmasking response characteristics of frog auditory nerve fibers: Comparison with the responses of midbrain auditory neurons. $\mathrm{J}$. Comp. Physiol., 187: 699-712.

Mac Dougall-Shackleton, S.A., S.H. Hulse, T.Q. Gentner, and W. Wight (1998) Auditory scene analysis by European starlings (Sturnus vulgar$i s)$ : Perceptual segregation of tone sequences. J. Acoust. Soc. Am., 103: 3581-3587.

Michelsen, A., and B.B. Andersen (1989) Honeybees can be recruited by a mechanical model of a dancing bee. Naturwissenschaften, 76: 277280.

Michelsen, A., B.B. Andersen, J. Storm, W.H. Kirchner, and M. Lindauer (1992) How honeybees perceive communcation dances, studied by means of a mechanical model. Behav. Ecol. Sociobiol., 30: 143-150.

Moss, C.F., and A. Surlykke (2001) Auditory scene analysis by echolocation in bats. J. Acoust. Soc. Am., 110: 2207-2226.

Mounjoy, D.J., and R.E. Lemon (1991) Song as an attractant for male and female European starlings, and the influence of song complexity on their response. Behav. Ecol. Sociobiol., 28: 97100.

Mounjoy, D.J., and R.E. Lemon (1996) Female choice for complex song in the European starling: a field experiment. Behav. Ecol. Sociobiol., 38: 65-71.

Narins, P.M., and R.R. Capranica (1978) Communicative significance of the two-note call of the treefrog Eleutherodactylus coqui. J. Comp. Physiol., 127: 1-9.

Nelson, D.A. (1988) Feature weighting in species song recognition by the field sparrow (Spizella pusilla). Behaviour, 106: 158-182.

Nelson, D.A., and L.J. Croner (1991) Song categories and their functions in the field sparrow. Auk, 108: 42-52.

Nottebohm, F. (1972) The origins of vocal learning. Am. Nat., 106: 116-140.

Ratcliffe, L., and R.G. Weisman (1986) Song sequence discrimination in the black-capped chickadee (Parus atricapillus). J. Comp. Psych. 100: 361-367.

Rheinlaender, J., H.C. Gerhardt, D.D. Yager, and R.R. Capranica (1979) Accuracy of phonotaxis by the Green Treefrog (Hyla cinerea). J. Comp. Physiol., 133: 247-255.

Richards, D.G. (1981) Alerting and message components in songs of rufous-sided towhees. Behaviour, 76: 223-249.

Rowe, C. (1999) Receiver psychology and the evolution of multicomponent signals. Anim. Behav., 58: 921-931.

Ryan, M.J. (1980) Female mate choice in a neotropical frog. Science, 209: 523-525.
Ryan, M.J. (1983) Sexual selection and communication in a neotropical frog, Physalaemus pustulosus. Evolution, 37: 261-272.

Ryan, M. J. (1985) The Túngara Frog, a Study in Sexual Selection and Communication. University of Chicago Press, Chicago, IL.

Ryan, M.J., and A.S. Rand (1990) The sensory basis of sexual selection for complex calls in the túngara frog, Physalaemus pustulosus (sexual selection for sensory exploitation). Evolution, 44: 305-314.

Ryan, M.J., J.H. Fox, W. Wilczynski, and A.S Rand (1990) Sexual selection for sensory exploitation in the frog Physalaemus pustulosus. Nature, 343: 66-67.

Schwartz, J.J. (1993) Male calling behavior, female discrimination and acoustic interference in the Neotropical treefrog Hyla microcephala under realistic acoustic conditions. Behav. Ecol. Sociobiol., 32: 401-414.

Schwartz, J.J., and H.C. Gerhardt (1989) Spatially mediated release from auditory masking in an anuran amphibian. J. Comp. Physiol., 166: $37-$ 41.

Schwartz, J.J., and H.C. Gerhardt (1995) Directionality of the auditory system and call pattern recognition during acoustic interference in the Gray Tree Frog, Hyla versicolor. Audit. Neurosci., 1: 195-206.

Searcy, W. A. (1992) Song repertoire and mate choice in birds. Am. Zool., 32: 71-80.

Vander Meer, R.K., C.S. Lofgren, and K.L. Baker (1990) The orientation inducer pheromone of the fire ant Solenopsis invicta. Physiol. Entomol., 15: 483-488.

Wightman F.L., and D.J. Kistler (1993) Sound localization. In Human Psychophysics (ed. by W.A. Yost, A.N. Popper and R.R. Fay), Springer-Verlag, New York, pp. 155-192.

Wilczynski, W., A.S. Rand, and M.J. Ryan (1999) Female preferences for temporal order of call components in the túngara frog: a Bayesian analysis. Anim. Behav., 58: 841-851.

Wollerman, L. (1999) Acoustic interference limits call detection in a Neotropical frog Hyla ebraccata. Anim. Behav., 57: 529-536.

Yost W.A., and S. Sheft (1993) Auditory perception. In Human Psychophysics (ed. by W.A Yost, A.N. Popper and R.R. Fay), Springer Verlag, New York, pp. 193-236.

Zar, J.H. (1999) Biostatistical Analysis. PrenticeHall, Inc., Upper Saddle River, NJ.

Zelick, R., and P.M. Narins (1988) The effects of noise on auditory processing and behavior in amphibians. In The Evolution of the Amphibian Auditory System (ed. by B. Fritzsch, M.J. Ryan, W. Wilczynski, T.E. Hetherington and W. Walkowiak), John Wiley and Sons, New York, pp. 511-536. 